\title{
Identification of a novel SDHB c.563 T > C mutation responsible for Paraganglioma syndrome and genetic analysis of the SDHB gene in China: a case report
}

\author{
Heye Chen ${ }^{1}$, Wei Yao ${ }^{2}$, Qing He${ }^{1}$, Xuefang Yu² and Bo Bian ${ }^{2 *}$ (D)
}

\begin{abstract}
Background: Pheochromocytoma/paraganglioma (PPGL) is a rare neuroendocrine tumor. Succinate dehydrogenase (SDH) deficiency has been confirmed to be associated with PPGL in various studies. SDHB mutations play an important role in PPGL. However, genetic screening of PPGL patients has not been widely carried out in clinics in China, and only a few related studies have been reported.

Case presentation: We report a case of a 23-year-old woman with paraganglioma (PGL) caused by a novel missense SDHB mutation, c.563 T > C (p.Leu188Pro), who presented with paroxysmal hypertension. Computed tomography (CT) and magnetic resonance imaging (MRI) revealed a PGL in the right retroperitoneum and no metastasis. The patient was treated with surgical excision and did not have postsurgerical paroxysmal hypertension. In addition, we searched the literature related to variations in SDHB genes in Chinese patients with PPGL using multiple online databases, including PubMed, China Hospital Knowledge Database and Wanfang Data. Ultimately, 14 studies (published between 2006 and 2019) comprising 34 cases of SDHB-related PGL or pheochromocytoma (PCC) were found. In total, 35 patients were enrolled in this study, and 25 mutations were identified. The common genetic alterations of SDHB in China were c.136C > T (11.4\%), c.18C > A (11.4\%) and c.725G > A (8.5\%). Some carriers of SDHB mutations (28.1\%) developed metastatic PPGL, and a high frequency of head and neck PGLs (HNPGLs) (59.4\%) was reported.
\end{abstract}

Conclusions: We describe a classic case with a novel SDHB c.563 T>C mutation. Based on our literature review, common SDHB gene mutations in Chinese PPGL patients are c.136C > T, c.18C > A and c.725G > A.

Keywords: Pheochromocytoma, Paraganglioma, Succinate dehydrogenase, Mutation, Metastasis, Case report

\section{Background}

Paraganglioma (PGL) and pheochromocytoma (PCC) are also referred to as pheochromocytoma/paraganglioma (PPGL), which are rare neuroendocrine tumors. These tumors may secrete catecholamines, which may cause paroxysmal hypertension, palpitations, headache and

\footnotetext{
*Correspondence: Bianbozyy@163.com

${ }^{2}$ Department of Cardiology, Tianjin Medical University General Hospital, Tianjin 300070, China

Full list of author information is available at the end of the article
}

diaphoresis and may eventually lead to serious cardiovascular complications.

Recent studies have shown that approximately $1 / 3$ of PPGL patients have a genetic background [1]. It has also been reported that approximately $40 \%$ of all PGLs and $3 \%$ of all PCCs are associated with succinate dehydrogenase (SDH) deficiency [2]. SDH, which is a respiratory enzyme, plays a key role that links the Krebs cycle and the electron transport chain, and $\mathrm{SDH}$ is regulated by SDHA, SDHB, SDHC and SDHD [3]. SDHB, which 
contains two highly conserved L(I)YR motifs, is the Fe-S subunit of complex II [4]. The two L(I)YR motifs are necessary for Fe-S clusters via recruitment of the Fe-S transfer machinery [4].

In many cases, SDHB-related disease is characterized by a single tumor [5], and carriers of gene variants commonly develop extra-adrenal PGLs, PCCs and metastatic disease than do carriers of mutations in the other SDH subunits [6-8]. In addition, SDHB-related PPGLs are reported to be associated with malignancy rates as high as 7.7-97\% [6-12].

At present, genetic screening of PPGL patients has not been widely carried out in Chinese clinics, and only a few related studies have been conducted. The aims of the study are to report a novel SDHB c.563 T > C mutation and to investigate SDHB variations in Chinese PPGL patients. Therefore, we collected all literature related to SDHB variations in PPGL in Chinese people.

\section{Case presentation}

A 23-year-old female presented with complaints of paroxysmal hypertension (the highest BP was 230/180 $\mathrm{mmHg}$ ) with palpitations, headache, diaphoresis and vomiting for 11 months. All of her sudden hypertension attacks were treated with antihypertensive drugs. Three days prior, the patient presented to the emergency department again with paroxysmal hypertension (BP 173/ $139 \mathrm{mmHg}$ ) and the above symptoms, but obvious abnormalities were not found on physical examination. One year prior, she had undergone laparoscopic cholecystectomy for gallstones. In addition, she had no history of other systemic diseases.

After an extensive workup, the patient was found to have elevations of plasma methoxynorepinephrine and urine vanillylmandelic acid, but her plasma metanephrine level was normal (Table 1).

Subsequent CT and MRI showed a $4.6 \times 3.1 \mathrm{~cm}$ retroperitoneal mass on the right retroperitoneum, and the boundary between the mass and the inferior vena cava (IVC) was not clear (Fig. 1). Enhanced CT scanning of the thorax, abdomen and pelvic cavities showed no metastasis. Before admission, the patient had undergone cervical CT because of the symptoms mentioned above, and the results were normal. However, considering the clinical history and inapparent bilateral adrenal glands, we favored the clinical diagnosis of retroperitoneal PGL.

Table 1 Biochemical characteristics

\begin{tabular}{lll}
\hline & Data & Reference range \\
\hline metanephrine $(\mathrm{nmol} / \mathrm{l})$ & $<0.08$ & $\leq 0.5$ \\
methoxynorepinephrine $(\mathrm{nmol} / \mathrm{l})$ & $>20.56$ & $\leq 0.90$ \\
urine vanillylmandelic acid $(\mu \mathrm{mol} / 24 \mathrm{~h})$ & 119.9265 & $<68.60$ \\
\hline
\end{tabular}

The patient was given doxazosin and metoprolol for 2 weeks as preoperative preparation. Then, the patient was medically managed with surgical excision. Immunohistochemical staining: Syn and CgA were positive, Melan A, HMB45 and $\alpha$-inhibin were negative, S-100 cells were positive, and the CD31 vascular endothelium marker was positive. Conclusion: right retroperitoneal PGL (Fig. 1). However, the local capsule of the tumor was incomplete.

To further determine the cause of the disease, we performed genetic testing with consent from the patient. Genetic testing demonstrated that the patient carried a missense mutation in exon 6 of the SDHB gene [c.563 $\mathrm{T}>\mathrm{C}]$ (Fig. 2). The identified mutation was classified as likely pathogenic (class 1). This variation is novel, and there are no relevant research reports at present. Since the patient is an orphan, we could not obtain her pedigree for the SDHB-linked family.

Clinical follow-up examinations were carried out three times through telephone interviews or outpatient visits. One year after surgery, the patient did not exhibit paroxysmal hypertension (BP 90-110/60-70 $\mathrm{mmHg}$ ) or the symptoms described above. Meanwhile, an abdominal CT scan did not indicate any masses. However, it will be necessary to perform long-term follow-up and screening of this patient over her lifetime.

\section{Discussion and conclusion}

With widespread PPGL genetic testing, the clinical manifestations of many PPGL-related genes have become well understood. Our study reports a novel SDHB c.563 $\mathrm{T}>\mathrm{C}$ mutation. To date, Human Gene Mutation Database (HGDM, http://www.hgmd.cf.ac.uk/) includes 254 SDHB gene mutations, but the c.563 $\mathrm{T}>\mathrm{C}$ variant has not been reported. This specific case adds to our knowledge of PCCs and PGLs and may help with genetic counseling of patients.

However, genetic screening of PPGL patients has not been widely carried out in Chinese clinics, and few related studies have been conducted. Therefore, to analyze and evaluate the variations of SDHB genes in Chinese patients with PPGL, we carried out a systematic literature review using multiple online databases, including China Hospital Knowledge Database (CNKI) (http:// www.chkd.cnki.net), Wanfang Data (http://www.wanfangdata.com.cn/), and PubMed (https://www.ncbi.nlm. nih.gov/pubmed), by using the key words "SDHB," and "China". The references listed in the relevant studies were carefully screened to identify additional studies. In total, 15 studies (published between 2006 and 2019) were identified (Table 2), comprising 35 cases (including the current case) of SDHB-related PGL or PCC .

The patients included 35.4\% (11/31) males and 64.5\% $(20 / 31)$ females, and the mean age at first evaluation was $31.9 \pm 11.9$ years (range: $12-58$ years). Of the 35 patients 

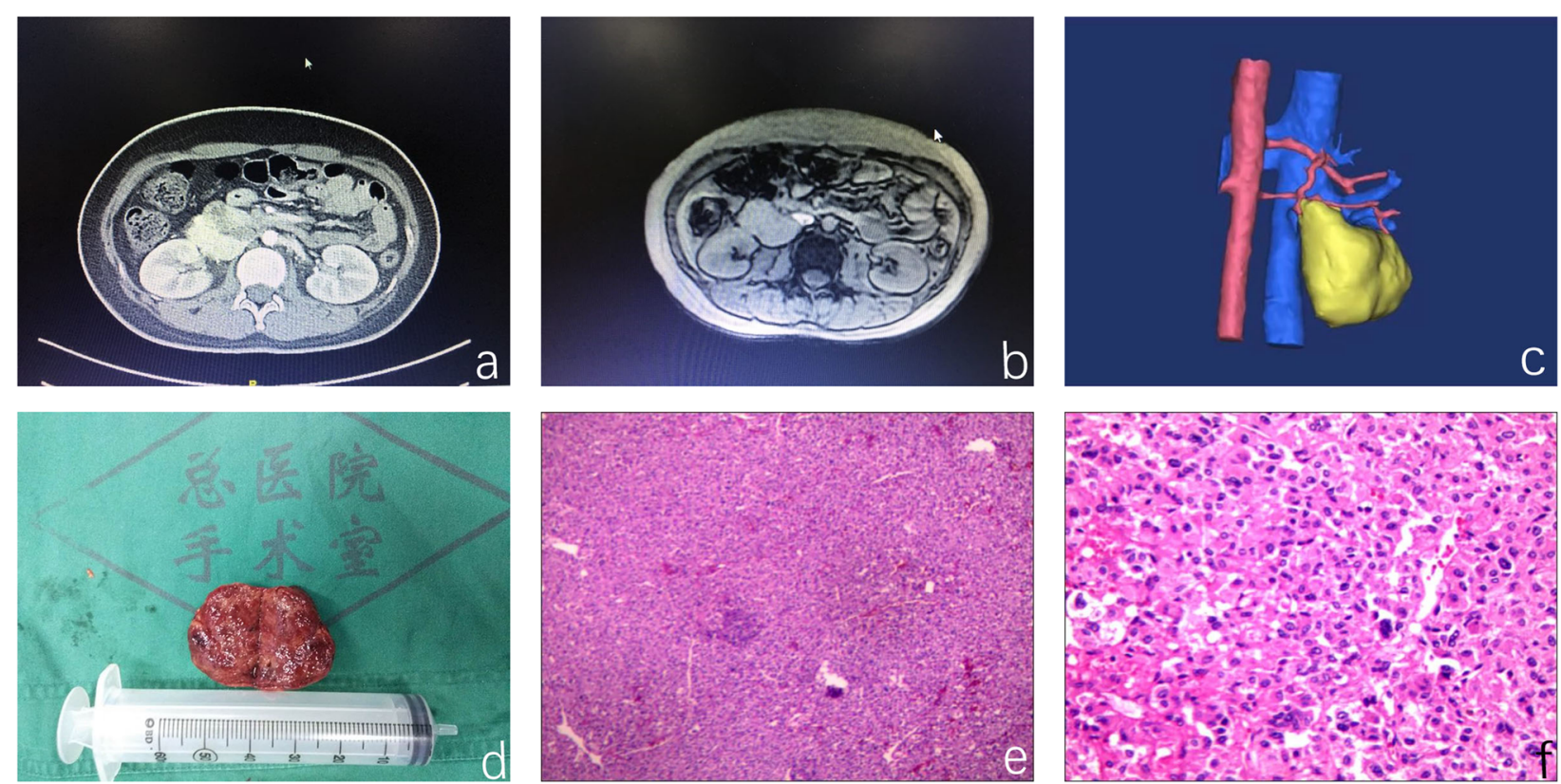

Fig. 1 a-c CT and MRI showed a $4.6 \times 3.1 \mathrm{~cm}$ retroperitoneal mass on the right retroperitoneum, and the boundary between the mass and the IVC was not clear; d-f Pathology and immunohistochemical staining: Syn and CgA were positive, Melan A, HMB45 and a-inhibin were negative, S100 cells were positive, and the CD31 vascular endothelium marker was positive

diagnosed with PPGL, 54.5\% (18/33) of primary tumors were in the head and neck, 9.1\% (3/33) were in the adrenal gland, and 33.4\% (11/33) were in an extra-adrenal gland. In addition, 9/32 (28.1\%) carriers of SDHB mutations developed metastatic PPGL, including 5 cases of head and neck paragangliomas (HNPGLs), 1 case of PCC and 3 cases of extra-adrenal sympathetic paraganglioma (sPGL). Although previous studies have shown much higher rates for the development of sPGLs (approximately 60\%) [7, 12, 27], the frequency of HNPGLs among SDHB mutation carriers was high in our study, at approximately $59.4 \%$. Recently, French [28] and Dutch [11] groups published mutation studies of SDHB with proportions similar to those reported in our study, and the prevalence rates of PCC and sPGLs in their studies were 1.6 and $6.5 \%$ or 2.1 and $13.4 \%$, respectively. There was a high proportion of index patients in previous studies, which could lead to ascertainment bias and underestimation of the proportion of HNPGLs. In addition, our review includes three HNPGL studies, which may increase the proportion of HNPGLs among SDHB mutation carriers.

In our study, 9/32 (28.1\%) SDHB mutation carriers developed metastatic PGL/PCC, which included 5 cases of HNPGLs, 1 case of PCC and 3 cases of sPGLs. The rate of metastatic disease was lower than that reported in previous studies $[6,8,9,12]$. Some have proposed that selection bias in referral-based studies is a major reason for a very high rate of malignant PGL in SDHB mutation carriers. In addition, we suggest that recurrent and malignant tumors might occur years after primary PPGL surgery; thus, the prevalence of recurrence and malignancy may be underestimated. In other words, the

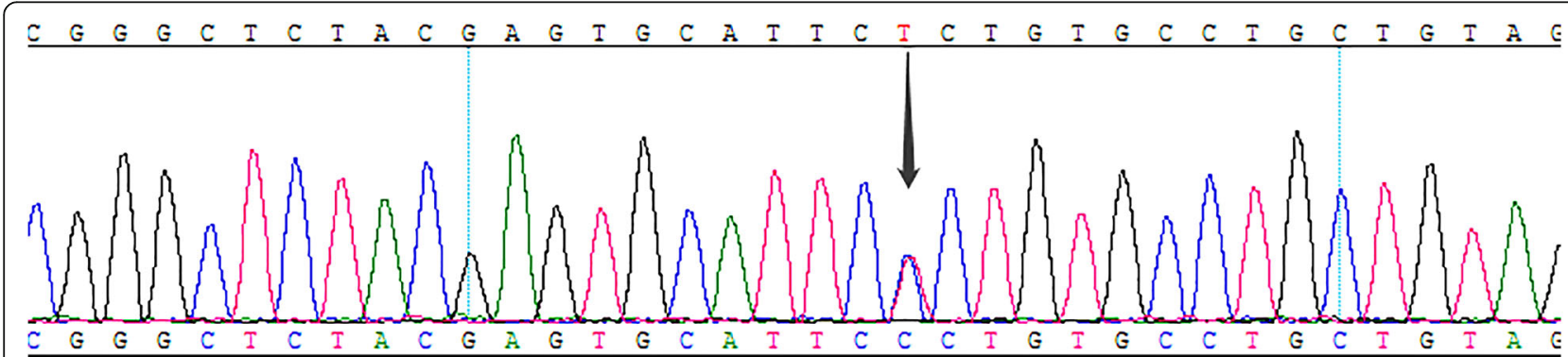

Fig. 2 The novel variant of the SDHB gene: Genomic DNA analysis of peripheral blood leukocytes, showing a germline missense mutation in exon 6 of the SDHB gene [c.563 T > C] (arrow) 
Table 2 Characterization of Fifteen Related Studies on SDHB Mutations in PPGL Patients

\begin{tabular}{|c|c|c|c|c|c|c|c|c|c|c|}
\hline Reference & Year & Age & Sex & Exon & CDNA & Protein & Type & PGL/PCC & Location & Malignant disease \\
\hline \multirow[t]{2}{*}{ [13] } & \multirow[t]{2}{*}{2006} & 32 & $F$ & 7 & c.689G $>A$ & p.R230H & Missense & PGL & Para-aortic abdominal & No \\
\hline & & 17 & M & 7 & c.757delT & p.C253Vfs $257 X$ & Frameshift & PGL & Middle mediastinum & Yes \\
\hline [14] & 2007 & 22 & $\mathrm{~F}$ & 7 & c. $640 \mathrm{C}>\mathrm{T}$ & p.Q214X & Nonsense & $\mathrm{PCC}^{\mathrm{a}}$ & Left adrenal gland & No \\
\hline \multirow[t]{3}{*}{ [15] } & \multirow[t]{3}{*}{2009} & 15 & $\mathrm{~F}$ & 2 & c. $136 \mathrm{C}>\mathrm{T}$ & p.R46X & Nonsense & $P G L^{a}$ & Postcaval abdominal & No \\
\hline & & 39 & F & 3 & c. $268 \mathrm{C}>\mathrm{T}$ & p.R90X & Nonsense & PGL & Para-aortic abdominal & Yes \\
\hline & & 22 & $\mathrm{~F}$ & 7 & c. $725 \mathrm{G}>\mathrm{A}$ & $\mathrm{p} . \mathrm{R} 242 \mathrm{H}$ & Missense & PCC & Right adrenal gland & No \\
\hline \multirow[t]{10}{*}{ [16] } & \multirow[t]{10}{*}{2010} & 53 & $\mathrm{~F}$ & 3 & c. $269 \mathrm{G}>\mathrm{A}$ & p.R90E & Missense & PGL & HN/RCBT & No \\
\hline & & 36 & $\mathrm{~F}$ & 6 & C. $597 C>$ G & p.Y199X & Nonsense & PGL & $\mathrm{HN} / \mathrm{RCBT}$ & No \\
\hline & & 43 & F & 7 & c. $709 \mathrm{C}>\mathrm{T}$ & p.P237S & Missense & PGL & HN/RCBT & No \\
\hline & & 31 & $\mathrm{~F}$ & 2 & c. $200+1 G>C$ & p.? & Splice site & PGL & HN/RGJT & No \\
\hline & & 29 & $\mathrm{~F}$ & 1 & c.20-22delinsC & p.L7PrfsX55 & Frameshift & $P G L$ & HN/RGJT & Yes \\
\hline & & 31 & $F$ & 7 & c. $725 \mathrm{G}>\mathrm{A}$ & p.R242H & Missense & PGL & HN/RGJT & No \\
\hline & & 37 & F & 7 & c. $725 \mathrm{G}>\mathrm{A}$ & p.R242H & Missense & PGL & HN/RGTT & No \\
\hline & & 33 & M & 2 & c. $79 \mathrm{C}>\mathrm{A}$ & p.R27X & Nonsense & PGL & HN/LCBT & No \\
\hline & & 38 & F & 6 & c. $597 C>$ G & p.Y199X & Nonsense & PGL & HN/RCBT & No \\
\hline & & 30 & $\mathrm{~F}$ & 2 & c. $137 \mathrm{G}>\mathrm{A}$ & p.R46Q & Missense & PGL & HN/LCBT & No \\
\hline \multirow[t]{2}{*}{ [17] } & \multirow[t]{2}{*}{2010} & NA & NA & 6 & c.591del C & p.S198Afs219X & Frameshift & NA & NA & NA \\
\hline & & NA & NA & 7 & c. $688 \mathrm{C}>\mathrm{T}$ & p.R230C & Missense & NA & NA & NA \\
\hline [18] & 2011 & NA & NA & 2 & c. $136 C>T$ & p.R46X & Nonsense & NA & NA & NA \\
\hline \multirow[t]{6}{*}{ [19] } & \multirow[t]{6}{*}{2013} & 58 & M & 6 & C. $595 C>A$ & p.S195R & Missense & PGL & $\mathrm{HN}$ & No \\
\hline & & 30 & $\mathrm{~F}$ & 1 & C. $18 \mathrm{C}>\mathrm{A}$ & p.A6A & Synonymous & PGL & $\mathrm{HN}$ & Yes \\
\hline & & 17 & M & 1 & C. $18 \mathrm{C}>\mathrm{A}$ & p.A6A & Synonymous & PGL & $\mathrm{HN}$ & Yes \\
\hline & & 47 & $\mathrm{~F}$ & 6 & C. $595 C>A$ & p.S195R & Missense & PGL & $\mathrm{HN}$ & No \\
\hline & & 29 & F & 1 & c. $18 \mathrm{C}>\mathrm{A}$ & p.A6A & Synonymous & PGL & $\mathrm{HN}$ & Yes \\
\hline & & 37 & M & 1 & C. $18 \mathrm{C}>\mathrm{A}$ & p.A6A & Synonymous & PGL & $\mathrm{HN}$ & No \\
\hline [20] & 2014 & 30 & M & 4 & c. $380 \mathrm{~T}>\mathrm{G}$ & p.1127s & Missense & $P G L^{b}$ & Abdominal $\rightarrow \mathrm{HN}$ & No \\
\hline [21] & 2015 & 30 & NA & 2 & c.112delC & p.R38Vfs77X & Frameshift & PGL & Bladder & Yes \\
\hline \multirow[t]{2}{*}{ [22] } & \multirow[t]{2}{*}{2015} & 54 & M & 7 & c. $647 \mathrm{~A}>\mathrm{G}$ & p.Y216C & Missense & PGL & $\mathrm{HN}$ & No \\
\hline & & 38 & M & - & Del exon $1,2,3,7,8$ & - & Large deletion & PGL & $\mathrm{HN}$ & Yes \\
\hline \multirow[t]{2}{*}{ [23] } & \multirow[t]{2}{*}{2018} & 14 & M & 4 & c.343C > T & p.R115X & Nonsense & PGL & Postcaval abdominal & No \\
\hline & & 32 & M & 5 & c. $541-542 A>G$ & IVS5-2A > G & Splice site & PGL & Para-aortic abdominal & No \\
\hline [24] & 2018 & 46 & M & 2 & c. $136 \mathrm{C}>\mathrm{T}$ & p.R46X & Nonsense & PCC & Right adrenal gland & Yes \\
\hline [25] & 2018 & 12 & $\mathrm{~F}$ & 2 & c. $136 \mathrm{C}>\mathrm{T}$ & p.R46X & Nonsense & PGL & Upper left mediastinum & No \\
\hline [26] & 2019 & 16 & $\mathrm{~F}$ & 4 & $c .423+1 G>T$ & p.? & Splice site & PGL & Retroperitoneal & No \\
\hline Current case & 2019 & 23 & $\mathrm{~F}$ & 6 & C.563 T > C & p.L188P & Missense & PGL & Retroperitoneal & No \\
\hline
\end{tabular}

CBT Carotid body tumor, GJT Glomus jugulare tumor, GGT Glomus tympanicum tumor, NA Not applicable.

a palindromic tumors

${ }^{b}$ multiple tumors

discrepancy in malignancy rates may be linked to the different follow-up times.

In addition, for HNPGL patients, the rate of metastatic diseases was $15.6 \%$ (5/32), which was higher than the rates observed for sPGL and PCC patients. Therefore, patients with HNPGL have a high malignancy risk. Moreover, a recent study reported that patients with $\mathrm{SDH}$ mutation have a higher risk of later development of metachronous tumors and recurrence than do patients without mutation in this gene [29]. In summary, radiological screening is very important among carriers of SDHB mutations, and follow-up of those patients, especially the head and neck region, should be undertaken.

Of the 35 SDHB gene variants, we found 25 different mutations, and SDHB pathogenic mutations included missense mutations $(n=10)$, nonsense mutations $(n=6)$, 
frameshift mutations $(n=4)$, splice site mutations $(n=$ $3)$, synonymous mutations $(\mathrm{n}=1)$, and deletions of one or more exons $(n=1)$. Common genetic alterations of SDHB in Chinese patients included c.136C > T (11.4\%), c. $18 \mathrm{C}>\mathrm{A}(11.4 \%)$ and c.725G > A (8.5\%). The c.136C > T (p.R46X) mutation and the c.725G > A (p.R242H) mutation occur in the first highly conserved (I44Y45R46) motif of SDHB and the second (L240Y241R240) motif, which are essential for incorporation of the Fe-S cluster into SDHB [4, 30]. Fe-S clusters are vitally important to electron transport and function, and this mutation completely abrogates SDH activity. However, the c.18C $>$ A (p.A6A) mutation is a synonymous mutation, and $3 / 4$ of carriers of this variation have metastatic disease. Thus, we suggest that c.18C > A may be one of the phenotypic causes of HNPGLs.

Interestingly, in our results, three frameshift mutations (c.757delT, c.20-22delinsC and c.112delC) were associated with metastatic disease. The term frameshift mutation refers to a change of the reading frame, resulting in the original gene encoding one peptide chain and the variant gene encoding a completely different peptide chain sequence. This change may render PPGL caused by frameshift mutations prone to metastasis, which highlights the necessity of follow-up for those patients.

Finally, our results have some limitations. On the one hand, few related studies have been performed in China, and some studies that lacked complete data were excluded. This inevitably led to limited case collection, which could lead to unreliable results. On the other hand, we did not perform genomic analysis of family members, which limits our ability to assess the association of PPGL morbidity with SDHB mutations. Moreover, without functional studies, we cannot determine the true pathogenicity of SDHB mutations.

In conclusion, we report a novel SDHB c.563 T > C mutation and investigate SDHB mutations among PPGL patients in China in this literature review. Thus, it is necessary to develop genetic screening for PPGL patients to guide diagnosis, treatment and follow-up. Large studies of SDHB mutations are needed to analyze the characteristics of these patients in China.

\section{Abbreviations \\ PPGL: Pheochromocytoma/paraganglioma; PGL: Paraganglioma; PCC: Pheochromocytoma; SDH: Succinate dehydrogenase; IVC: Inferior vena cava; CT: Computed tomography; MRI: Magnetic resonance imaging; HGDM: Human Gene Mutation Database; CNKI: China Hospital Knowledge Database; HNPGLs: Head and neck paragangliomas; sPGLs: Extra-adrenal sympathetic paragangliomas}

\section{Acknowledgments}

We are deeply grateful to the patient's family for providing medical records and medical images for our research and to the clinicians for their contributions to this study.

\section{Authors' contributions}

$\mathrm{HC}$ drafted the manuscript; $\mathrm{BB}$ and $\mathrm{QH}$ revised the manuscript; $\mathrm{WY}$ and $\mathrm{XY}$ performed the clinical literature review; and the authors read and approved the manuscript.

\section{Funding}

This study was funded by the Fund of Tianjin Health Planning Commission (2015KZ117). The funding bodies played no role in the design of the study, the collection, analysis, and interpretation of the data or the writing of the manuscript.

\section{Availability of data and materials}

The sequence datasets generated during the current study are not publicly available because it is possible that individual privacy could be compromised.

Ethics approval and consent to participate

All procedures involving human subjects were approved by the ethics committee of Tianjin Medical University General Hospital.

\section{Consent for publication}

The patient provided written informed consent for the publication of clinical details, and clinical images were obtained.

\section{Competing interests}

The authors declare that they have no competing interests.

\section{Author details}

${ }^{1}$ Department of Endocrinology and Metabolism, Tianjin Medical University General Hospital, Tianjin 300070, China. ${ }^{2}$ Department of Cardiology, Tianjin Medical University General Hospital, Tianjin 300070, China.

Received: 2 March 2020 Accepted: 11 May 2020

Published online: 27 May 2020

\section{References}

1. Fishbein L, Nathanson KL. Pheochromocytoma and paraganglioma: understanding the complexities of the genetic background. Cancer Genet. 2012:205(1-2):1-11.

2. Gill AJ, Benn DE, Chou A, Clarkson A, Muljono A, Meyer-Rochow GY, et al. Immunohistochemistry for SDHB triages genetic testing of SDHB, SDHC, and SDHD in paraganglioma-pheochromocytoma syndromes. Hum Pathol. 2010;41(6):805-14

3. Gill AJ. Succinate dehydrogenase (SDH) and mitochondrial driven neoplasia. Pathology. 2012;44(4):285-92

4. Maio N, Singh A, Uhrigshardt $H$, Saxena N, Tong WH, Rouault TA. Cochaperone binding to LYR motifs confers specificity of iron sulfur cluster delivery. Cell Metab. 2014;19(3):445-57.

5. Gimenez-Roqueplo AP, Dahia PL, Robledo M. An update on the genetics of paraganglioma, pheochromocytoma, and associated hereditary syndromes. Horm Metab Res. 2012:44(5):328-33.

6. Neumann HP, Pawlu C, Peczkowska M, Bausch B, McWhinney SR, Muresan $\mathrm{M}$, et al. Distinct clinical features of paraganglioma syndromes associated with SDHB and SDHD gene mutations. JAMA. 2004;292(8):943-51.

7. Benn DE, Gimenez-Roqueplo AP, Reilly JR, Bertherat J, Burgess J, Byth K, et al. Clinical presentation and penetrance of pheochromocytoma/ paraganglioma syndromes. J Clin Endocrinol Metab. 2006:91(3):827-36.

8. Timmers HJ, Kozupa A, Eisenhofer G, Raygada M, Adams KT, Solis D, et al. Clinical presentations, biochemical phenotypes, and genotype-phenotype correlations in patients with succinate dehydrogenase subunit B-associated pheochromocytomas and paragangliomas. J Clin Endocrinol Metab. 2007; 92(3):779-86.

9. Amar L, Bertherat J, Baudin E, Ajzenberg C, Bressac-de Paillerets B, Chabre O, et al. Genetic testing in pheochromocytoma or functional paraganglioma. J Clin Oncol. 2005;23(34):8812-8

10. Srirangalingam U, Walker L, Khoo B, MacDonald F, Gardner D, Wilkin TJ, et al. Clinical manifestations of familial paraganglioma and phaeochromocytomas in succinate dehydrogenase $\mathrm{B}(\mathrm{SDH}-\mathrm{B})$ gene mutation carriers. Clin Endocrinol (Oxf). 2008;69(4):587-96. 
11. Niemeijer ND, Rijken JA, Eijkelenkamp K, van der Horst-Schrivers ANA, Kerstens MN, Tops CMJ, et al. The phenotype of SDHB germline mutation carriers: a nationwide study. Eur J Endocrinol. 2017;177(2):115-25.

12. Jochmanova I, Wolf Kl, King KS, Nambuba J, Wesley R, Martucci V, et al. SDHB-related pheochromocytoma and paraganglioma penetrance and genotype-phenotype correlations. J Cancer Res Clin Oncol. 2017;143(8): 1421-35.

13. Zhou YR. Study on the gene of pheochromocytoma and the related factors of hypoxia. Doctor's thesis. Beijing: China Union Medical University; 2006.

14. Reusch J, Haag C, Raue F, Badenhoop K. Relapsing pheochromocytoma in a Chinese women caused by a novel mutation in exon 6 of the SDHB gene: a case report. Exp Clin Endocrinol Diabetes. 2007;115(9):616-8.

15. Zheng XL, Wang WQ, Su TW, Zhou WW, Jiang L, Ning G. Mutation of SDHB gene in sporadic patients with pheochromocytoma. Chin J Endocrinol Metab. 2009:25:423-5.

16. Cha Y. Study on the pathogenicity of succinate dehydrogenase gene in the Paraganglioma of head and neck. Doctor's thesis. Beijing: Peking Union Medical College; 2010

17. Wu DJ, Zhou XO, Gao PJ, Zhu DL. The development and verification of Gene Chip in the detection of genetic mutations of Pheochromocytoma. Chin J Clin Med. 2010;17:1-3.

18. Zu TJ, Jia MY, Yuan RT, Bu LX, Yao RY. The mutations of germline succinate dehydrogrnase subunit B (SDHB) in sporadic paragangliomas. Shanghai Kou Qiang Yi Xue. 2011;20(4):413-6.

19. Wei SF. Study of clinical -pathological characteristics and related gene mutation in Head \& Neck paragangliomas. Doctor's thesis. Tianjin: Tianjin Medical University; 2013.

20. Wu YX, Que XG, He SL, Zhao LF. Metastatic paraganglioma of skull: a case report and literature review. Chin J Minim Invasive Neurosurg. 2014;19:1367.

21. Lee CH, Cheung CY, Chow WS, Woo YC, Yeung CY, Lang BH, et al. Genetics of apparently sporadic Pheochromocytoma and Paraganglioma in a Chinese population. Horm Metab Res. 2015;47(11):833-8.

22. Zhu WD, Wang ZY, Chai YC, Wang XW, Chen DY, Wu H. Germline mutations and genotype-phenotype associations in head and neck paraganglioma patients with negative family history in China. Eur J Med Genet. 2015;58(9): 433-8.

23. Huang Y, Wang LA, Xie Q, Pang J, Wang L, Yi Y, et al. Germline SDHB and SDHD mutations in pheochromocytoma and paraganglioma patients. Endocr Connect. 2018;7(12):1217-25.

24. Wu K, Zhang Y, Zhang H, Tan ZH, Guo XH, Yang JM. Germline gene testing of the RET, VHL, SDHD and SDHB genes in patients with pheochromocytoma/paraganglioma. Beijing Da Xue Xue Bao. 2018;50(4): 634-9.

25. Qian JH, XU T, Cheng XY, Qin YM, Yang SW. Left superior mediastinal pheochromocytoma in children associated with SDHB gene mutation: a case report and literature review. Jiangsu Med J. 2018:44:463-5.

26. Gao Y. Clinical analysis of a novel splicing mutation of SDHB gene inducing paraganglioma near inferior vena cava. Master's thesis. Zhengzhou: Zhengzhou University; 2019.

27. Tufton N, Shapiro L, Srirangalingam U, Richards P, Sahdev A, Kumar AV, et al. Outcomes of annual surveillance imaging in an adult and paediatric cohort of succinate dehydrogenase B mutation carriers. Clin Endocrinol (Oxf). 2017;86(2):286-96.

28. Gimenez-Roqueplo AP, Caumont-Prim A, Houzard C, Hignette C, Hernigou A, Halimi $P$, et al. Imaging work-up for screening of paraganglioma and pheochromocytoma in SDHx mutation carriers: a multicenter prospective study from the PGL.EVA investigators. J Clin Endocrinol Metab. 2013;98(1): $162-73$

29. Sen I, Young WF Jr, Kasperbauer JL, Polonis K, Harmsen WS, Colglazier JJ, et al. Tumor-specific prognosis of mutation-positive patients with head and neck paragangliomas. J Vasc Surg. 2020;71(5):1602-12.

30. Saxena N, Maio N, Crooks DR, Ricketts CJ, Yang Y, Wei MH, et al. SDHBdeficient cancers: the role of mutations that impair iron sulfur cluster delivery. J Natl Cancer Inst. 2016;108(1):dvj287. https://doi.org/10.1093/jnci/ djv287.

\section{Publisher's Note}

Springer Nature remains neutral with regard to jurisdictional claims in published maps and institutional affiliations.

\section{Ready to submit your research? Choose BMC and benefit from:}

- fast, convenient online submission

- thorough peer review by experienced researchers in your field

- rapid publication on acceptance

- support for research data, including large and complex data types

- gold Open Access which fosters wider collaboration and increased citations

- maximum visibility for your research: over $100 \mathrm{M}$ website views per year

At $\mathrm{BMC}$, research is always in progress.

Learn more biomedcentral.com/submissions 